\title{
THE IMPACT OF HYBRID AND ELECTRIC POWERTRAINS ON VEHICLE DYNAMICS, CONTROL SYSTEMS AND ENERGY REGENERATION
}

\author{
David A. Crolla ${ }^{1}$ and Dongpu $\mathrm{Cao}^{2 *}$ \\ ${ }^{1}$ Institute for Automotive and Manufacturing Advanced Practice (AMAP), University of \\ Sunderland, Sunderland SR5 3XB, UK \\ ${ }^{2}$ Department of Engineering, Lancaster University, Lancaster LA1 4YW, UK \\ Email: d.cao@lancaster.ac.uk \\ *Corresponding author.
}




\begin{abstract}
The background to the development of so-called 'green' or 'low carbon' vehicles continues to be relentlessly rehearsed throughout the literature. Research and development (R\&D) into novel powertrains - often based on electric or hybrid technology - has been dominating automotive engineering around the world for the first two decades of the twenty-first century. Inevitably, most of the $R \& D$ has focused on the powertrain technology and the energy management challenges. However, as new powertrains have started to become commercially available, their effects on other aspects of vehicle performance have become increasingly important. This paper focuses on the review of the integration of new electrified powertrains with the vehicle dynamics and control systems. The integration effects can be discussed in terms of three generic aspects of vehicle motions, namely roll-plane, pitch-plane, and yaw-plane, which however are strongly coupled. Topic on regenerative suspension is further discussed. It quickly becomes clear that this integration poses some interesting future engineering challenges to maintain currently accepted levels of ride, handling and stability performance.
\end{abstract}

\title{
KEYWORDS
}

Hybrid and electric vehicles; vehicle dynamics; chassis controls; brake blending; regenerative suspension; individual wheel motor (IWM) drive

\section{INTRODUCTION}

Vehicle electrification has been increasingly concerned, due to the fossil fuel crisis and the more and more stringent standards on vehicle emissions as well as safety [1, 2]. However, this poses considerable challenges and demands revolutionary alternatives to the well-established traditional vehicle technologies associated with the powertrains, the chassis design and layout, and the vehicle dynamics and stability [3, 4]. Significant efforts have been made in the control and energy management of the powertrain systems, where a comprehensive overview of control strategies and controller designs has recently been conducted in [5]. The study [5] highlighted a few key challenges related to practical implementation of the proposed control strategies, effectiveness of drive-cycle dependent performance evaluation, and method development for quantifying vehicle drivability. Apart from these, vehicle electrification also requires rapid advances in development of electric drives and alternative energy storage systems [6, 7]. The combined effects of these challenges add considerable difficulties in vehicle design and development, and yield complex dependencies among the vehicle dynamics and controls integration.

Unlike the research and development in alternative powertrains and associated energy management systems, the impact of vehicle electrification on vehicle dynamics and control systems has received minimal attention by far [3, 4, 8]. Rauh [4] presented the fundamentals of energy dissipation and regeneration in vehicle dynamics, based on which energy-efficient chassis systems were discussed by highlighting some selected recent technology advances at Daimler AG. Fundamental vehicle dynamics for conventional road vehicles have been fairly well understood, and various chassis control systems have also been developed, for contributing to enhanced vehicle dynamic performance and driving safety [3, 9-15].

In view of electric and hybrid vehicles, three generic aspects of vehicle motions need to be investigated, namely roll-plane, pitch-plane, and yaw-plane [3]. However, these three aspects of 
the vehicle motions are strongly coupled, which thus affect vehicle dynamics and controls in a very complex manner $[3,9]$. Figure 1 presents a schematic view of the generic vehicle motions and their indications to vehicle system dynamics, controls and energy regeneration/consumption. Although the vehicle motions are in a coupled manner, their main contributions to different aspects of vehicle dynamics, stability and performance characteristics can be partially decoupled. For instance, vehicle handling dynamics and directional stability are mostly influenced by vehicle lateral, yaw and roll motions, while vehicle ride, attitude control and road-holding (and road friendliness) are dominated by vehicle pitch-plane motions (vertical, pitch and longitudinal). In general, energy regeneration potentials are associated mainly with vehicle braking and secondarily with suspension damping, while certain energy consumption is associated with vehicle sideslip. This indicates that the energy regeneration/consumption is strongly coupled with vehicle dynamics (ride/handling/stability/braking) and controls.

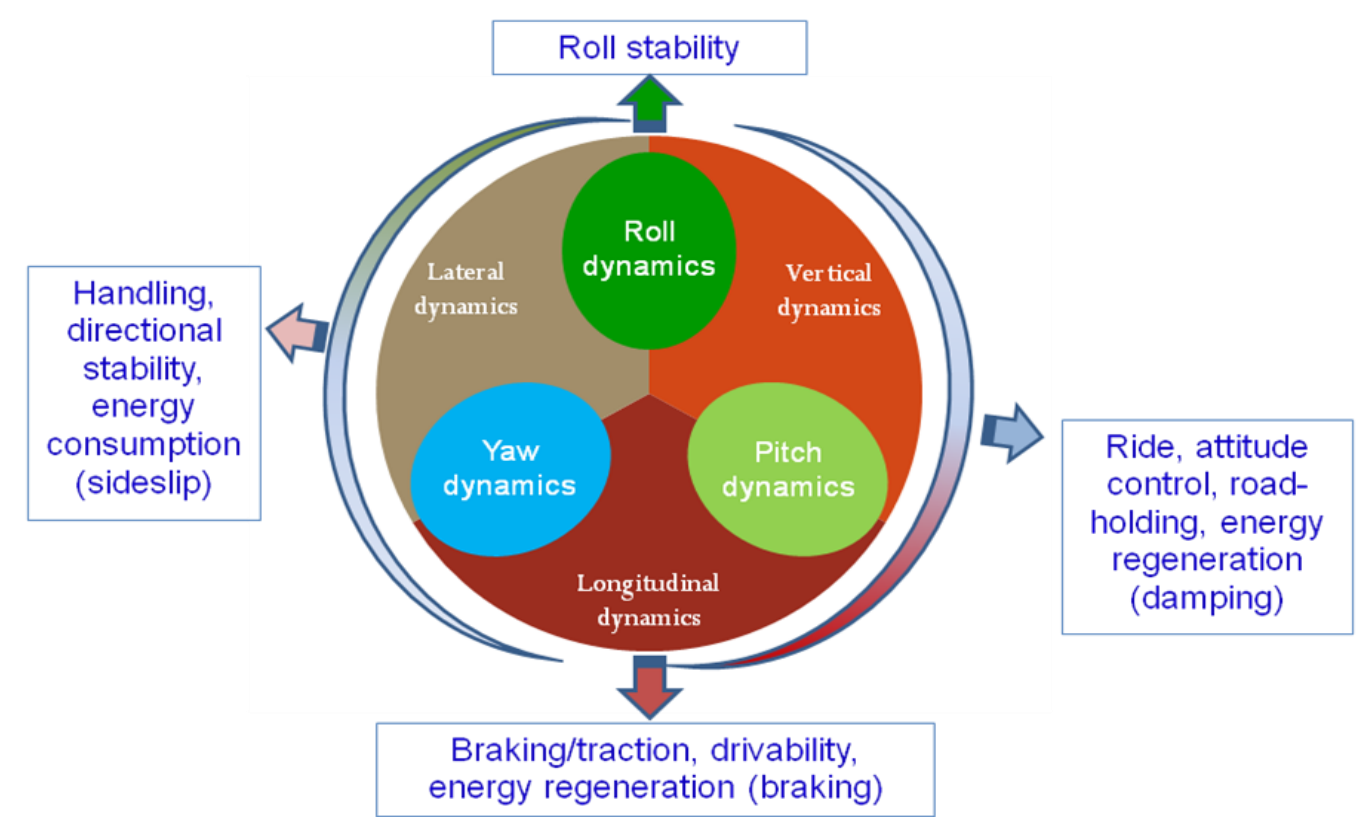

Fig. 1: Schematic view of generic vehicle motions and their indications to vehicle dynamics, controls and energy regeneration/consumption.

Further advances in vehicle dynamic characteristics and stability are likely to come from further exploitation of control systems, and in particular, the integration of controlled subsystems [1619], which have historically been developed independently, and the closed-loop driver-vehicle system controls [20,21]. The specific contribution of control system to enhancements in vehicle safety has recently been reviewed by Nagai [22], where the potential improvements associated with individual wheel motor (IWM) control, were highlighted.

The key component connecting electrified vehicle performance with vehicle dynamic behaviour is the electric motor. Electric motors have three recognised performance attributes [23-25]: (i) Extremely responsive and controllable to either torque or speed demand inputs; (ii) Reversible so that they are roughly equally efficient as either a motor or a generator; and (iii) High energy efficiency with efficiencies as high as $90 \%$. Depending upon the vehicle/chassis configuration, the motor might be arranged in series with another powerplant, at an individual axle, or as an IWM. A vehicle with four IWMs provides the significant potential of being able to control the tyre force at each of the vehicle corners independently [13, 23, 24]. 
Murata [24] presented the state of the art of IWMs from a Toyota viewpoint. The potential benefits in terms of improved vehicle controllability in driving, steering and braking were quantified and contrasted with the practical issues of designing an IWM to fit into the limited space available at the wheel station. It was concluded in [24] that the best packaging solution was to fit the IWM at the rear, unsteered wheels, which also has the benefits of providing rearwheel-drive (RWD) and more mass on the rear axle and can be assisted if necessary by fitting slightly wider wheels at the rear. In a prototype large saloon, the total mass of the rear driveline components was reduced by $36 \%$ in moving from a 'one motor + differential + driveshafts' arrangement to IWMs. The unsprung mass was only increased by $23 \%$.

Two early studies $[25,26]$ developed a complex control architecture with four neural adaptive controllers for the vehicle handling dynamics and an adaptive dynamic programming controller for the vehicle energy management. Another study [27] also tackled the problem in a generalised manner by distributing individual wheel force demands to each of the four corners from a central controller. This was even taken a stage further [28] by assuming each wheel to be steered independently. The safety implications of failure either of an individual wheel [29] or axle [30] motor inevitably pose some difficult challenges in practice. Recent work has explored an integrated control concept which integrates both the vehicle dynamics and energy management [31]. This is known to be challenging [32] since control systems have historically been developed as discrete sub-systems which have been added incrementally to the vehicle, e.g. antilock braking system (ABS), electronic stability program (ESP), active roll control (ARC), switchable dampers, active front steering (AFS), etc. The concept of an 'e-corner' has been proposed, probably by Siemens VDO initially, but the idea of a central controller which communicates with the four individual wheel modules where the forces are generated appears to offer an elegant solution [33].

However, most of the research work linking the performance of electric and hybrid vehicles with vehicle dynamic behaviour has tackled specific aspects of the problem, rather than dealing with the generalised case. In analysing vehicle dynamic behaviour, it is well understood that it is often separated into these categories as a convenient way of looking at primary effects. In practice, it is obviously the case that dynamic coupling occurs between the three coordinate directions, such as, the longitudinal forces - whether tractive or braking - can be employed to alter the directional characteristics through the yaw stability control (YSC), and the dynamic tyre loads controlled by vehicle suspension affect the ability of the tyres to develop longitudinal and lateral forces.

The overall aim of this paper is to review the integration of these new energy efficient powertrains with the vehicle dynamics and chassis controls, and in particular examine the effects on vehicle ride, handling and stability performance, and energy regeneration.

\section{IMPACT ON ROLL-PLANE DYNAMICS AND CONTTROLS}

Roll-plane vehicle dynamics and controls primarily concern vehicle roll stability, vertical ride vibrations, and road-holding, while vehicle roll motion is strongly coupled with lateral/yaw motions and thus handling characteristics [3, 34]. The integration of the electric and hybrid powertrains would alter the mass and inertia properties of the sprung as well as unsprung masses, and the height of vehicle centre of gravity (c.g.). The sprung mass and roll moment of inertia tend be increased, together with a higher vehicle c.g., mainly due to the substantial added mass of the batteries. With current technology, the battery packs are still extremely heavy; the scale of this problem is exemplified by the electric powered Tesla (weight of $1250 \mathrm{~kg}$ ) which has a 
battery pack weighing $450 \mathrm{~kg}$, while the Nissan Leaf and Mitsubishi i-MiEV electric cars have a battery pack of roughly $300 \mathrm{~kg}$. A significant increase in the unsprung mass arises when an IWM drive is employed, where a 20 50\% increase can be observed [24, 35, 36].

These associated variations in the mass and inertia properties and the vehicle c.g. height are generally undesirable in view of vehicle dynamics and controls. An increase in the sprung mass and the c.g. height indicates deteriorated roll stability and poses a higher challenge in vehicle roll controls. In addition, a heavier vehicle body combined with a higher c.g. tends to yield larger dynamic lateral load transfers during steering manoeuvres, which have negative effects in view of vehicle handling and directional stability controls. These would also pose extra challenges on maximizing braking energy recuperation (during braking-in-a-turn scenarios).

Traditional suspension tunings can be used to achieve a new compromise among the sprung mass vertical acceleration, suspension travel, and dynamic tire load, according to the variations in the sprung mass. However, such compromise might be deteriorated when an IWM drive is used. A larger unsprung mass tends to yield a considerable challenge in vertical wheel motion controls (for both road-holding and road friendliness), where optimal passive damping settings for vertical ride and road-holding might differ considerably upon the driving conditions. In addition, the IWM drive might require wider tires, suggesting a higher challenge in steering system design and suspension kinematics/packaging, and also slightly deteriorated roll stability limit. In terms of ride vibrations, a larger unsprung mass due to the IWM drive may yield a lower unpsrung mass natural frequency, which would undesirably be closer or even within the frequency range $(4-8 \mathrm{~Hz})$ that is most sensitive to human body in vertical direction [3].

Although the principles can be well understood and explained, considerable efforts need to be made to quantify the effects of electrified powertrains on vehicle roll dynamics/stability, vertical ride vibrations, and road-holding. Passive suspension design and tuning optimization and alternative semi-active suspension systems should be explored for enhancing both ride and roadholding qualities of IWM drive electric and hybrid vehicles. Controlled anti-roll bars together with semi-active dampers may further be investigated for realizing a better compromise among the roll-plane vehicle performance measures. For electrified vehicles with the IWMs employed only at one axle, a further suspension design/tuning compromise may exit for vertical wheel motion control of IWMs and vehicle roll moment distribution (thus handling balance and stability).

The use of controlled anti-roll bars and semi-active dampers could also be helpful in varying roll moment distribution between the front/rear axles, and thus vehicle steering/handling behaviours. In addition, the coordinated traction control with the controlled roll moment distribution can improve vehicle tractive performance during acceleration-in-a-turn manoeuvres. However, these control authorities are quite limited when driving on low-friction surfaces or at low lateralacceleration levels.

\section{IMPACT ON PITCH-PLANE DYNAMICS AND CONTROLS}

Pitch-plane vehicle dynamics and controls concern vehicle performance measures, such as traction/braking, drivability, pitch and vertical ride vibrations, pitch attitude control, and roadholding [3, 37]. Electric motor drives offer considerable potentials for enhanced traction control systems (TCS) compared with conventional IC engine vehicles (ICEVs). Electric motors are very responsive with time constants of the order of milliseconds, and they can be controlled either by torque or speed. In contrast, traction control systems for ICEVs, which typically may 
use both the braking system and the engine control, are much less responsive with time constants of the order of hundreds of milliseconds, and neither torque nor speed is directly controllable. The potential benefits only apply to vehicles in which the electric motor is the sole driving force of the vehicle, thus they are only relevant for fully electric vehicles and are not available for hybrid electric vehicles.

The traction control system for conventional vehicles does not control traction force directly. They attempt to prevent excessive longitudinal slip of the wheel. Controlling wheel slip within a limited range could maximise the available traction force and retain a lateral force capability to maintain vehicle directional stability. Therefore, despite the advantages of an electric motor drive, some fundamental problems remain with the estimation of wheel slip. Since the wheel speed can always be measured accurately, the problem still hinges on the accurate estimation or measurement of vehicle forward velocity.

Early work thus focused on devising a TCS which only required the available variables of motor torque and speed. A model following control (MFC) scheme was suggested [38, 39], which is based on the idea of the equivalent inertia of the driven wheels - including the effect of the vehicle mass providing sufficient friction force exists at the tyre/ground interface. Further work attempted to refine this simple approach to compromise stability and feedback gain [40-42]. It has also been tested on a prototype electric vehicle over differing surface conditions [38, 39]. However, this version of MFC has not proved to be sufficiently robust over a range of practical operating conditions $[43,44]$. The studies $[38,39]$ also devised an optimal slip ratio control based on the assumption that vehicle velocity measurement was available, so that an accurate estimate of wheel slip could be obtained. However, this approach still has the problem that the 'optimal' slip ratio depends on the tyre/ground condition, and so some form of road surface estimation is still required.

More recently, Yin and Hori [45-47] proposed an alternative approach, based on maximum transmittable torque estimation (MTTE), which does not require either vehicle velocity or information about the road-tyre conditions. The controller is based around controlling wheel torque directly, rather than wheel slip. It works effectively by estimating friction force via wheel torque and acceleration. Successful practical experiments were carried out on a small, singleseater prototype vehicle fitted with two rear wheel motors.

Regenerative braking is one of the most obvious benefits associated with vehicle electrification, by enhancing energy efficiency, particularly in city driving with frequent stop/go operations. However, there are two sets of limiting factors, suggesting that only a modest percentage of the available regeneration energy can be harvested. One set is associated with the actual process of regeneration, including:

(i) Battery state of charge (SOC);

(ii) Rate of charge of battery;

(iii) Battery temperature;

(iv) Generator power, speed and torque; and

(v) Overall efficiency - losses.

The other set is related to the overall braking performance of the vehicle. To achieve acceptable braking behaviour which is fully controllable by the driver, the regenerative braking must be integrated with the conventional hydraulic braking.

Conventional vehicle design involves a decision about the braking ratio between front and rear axles, where the design compromise is that the brake balance, normally a fixed ratio, is biased 
towards the front axle. If the regenerative braking is limited to modest levels (e.g., equivalent to conventional overrun conditions), then the effects on the brake balance are not likely to be a problem. However, if higher levels are used in an attempt to maximise the amount of energy recuperated, then it must be taken into account in the brake balance design.

The regenerative braking force is, rather obviously, only available at the axle connected to the motor/generator (MG) unit. In many mild hybrid applications, this will be the same as the axle driven by the IC engine - and so it has a negligible impact on the F:R force balance. However, in other schemes such as front-wheel-drive (FWD) hybrid with rear wheel motor assist, the F:R balance of forces will be modified during regenerative braking - and this could have a significant effect on the handling balance. The most obvious example with such a vehicle would occur during severe cornering; if the driver lifts off and regenerative braking is suddenly applied to the rear wheels, it may be sufficient to saturate the tyre force capabilities and cause an oversteer situation.

The simplest approach to gaining some braking regeneration energy is to control the MG unit to emulate conventional overrun braking, where the deceleration arises from the overrun torque on the engine. This appears to be straightforward, and has the attraction to the driver of retaining the feel of a traditional IC engined vehicle. However, there are a few issues to consider:

a) In a mild hybrid (e.g. integrated starter alternator (ISA)) or hybrid electric vehicle application, the engine overrun torque would preferably be disabled, e.g., by controlling the valves;

b) The amount of regeneration torque is controllable via the MG torque, but is limited by the fact that the MG speed decreases as the vehicle speed decreases; and

c) As the vehicle approaches a complete stop, the MG torque needs to be disabled analogous to depressing the clutch of an IC engine - to ensure smooth control via the hydraulic brakes at very low speed prior to stopping.

Certain efforts have recently been made on how to maximise the amount if energy recuperated during braking for different hybrid electric vehicle designs [48, 49]. One approach to optimising energy recovery is through the transmission controls, such as continuously variable transmissions (CVTs) [50] and infinitely variable transmissions (IVTs) [51]. The idea underlying these studies is basically the same; in the hybrid electric vehicle driving mode, the variable transmission is controlled to maintain the IC engine on or around its optimum operating line, and so in braking it is similarly controlled to maximise energy recuperated taking into account the MG efficiency map, battery SOC and driving conditions.

To optimise energy recovery demands an integrated control of the regenerative braking and the friction brakes [52]. The critical issue is the design of an independently controlled system for the friction brakes, where three approaches have been evaluated: (a) Brake-by-wire; (b) Electrohydraulic brakes [53]; and (c) Electromechanical brakes [54]. There is a fixed relationship between the driver pedal pressure and the braking forces in conventional hydraulic braking systems, which indicates that any regenerative braking can only be added to the existing braking system when the driver applies the brakes. But if the friction brakes can be controlled independently, then the net braking force on the vehicle can be a controlled blend of regenerative and friction braking, depending on the driving conditions.

Assuming such braking system hardware is available, the blending strategy is not entirely straightforward, and a simple example is shown in Fig. 2. It presents the time histories for a vehicle during a step braking manoeuvre with an initial speed of $28 \mathrm{~m} / \mathrm{s}$. The brakes are applied 
fairly rapidly over a 0.4 -second period and then held constant to provide a constant deceleration of $3 \mathrm{~m} / \mathrm{s}^{2}$. The description of a potential brake blending strategy can be summarised over the five phases:

I. Initial phase: accelerator pedal released and brakes applied, where initial deceleration is achieved by regenerative braking;

II. Deceleration demand increasing as brakes are applied: friction brakes begin to be deployed as well;

III. Constant deceleration: a balance between regenerative and friction braking is varied;

IV. As speed reduces, all the deceleration demand can be achieved by the regenerative brakes, so the friction brakes are released;

V. At low speed, when the vehicle is approaching a full stop, the regenerative brakes are blended out and the driver takes full control via the friction brakes.

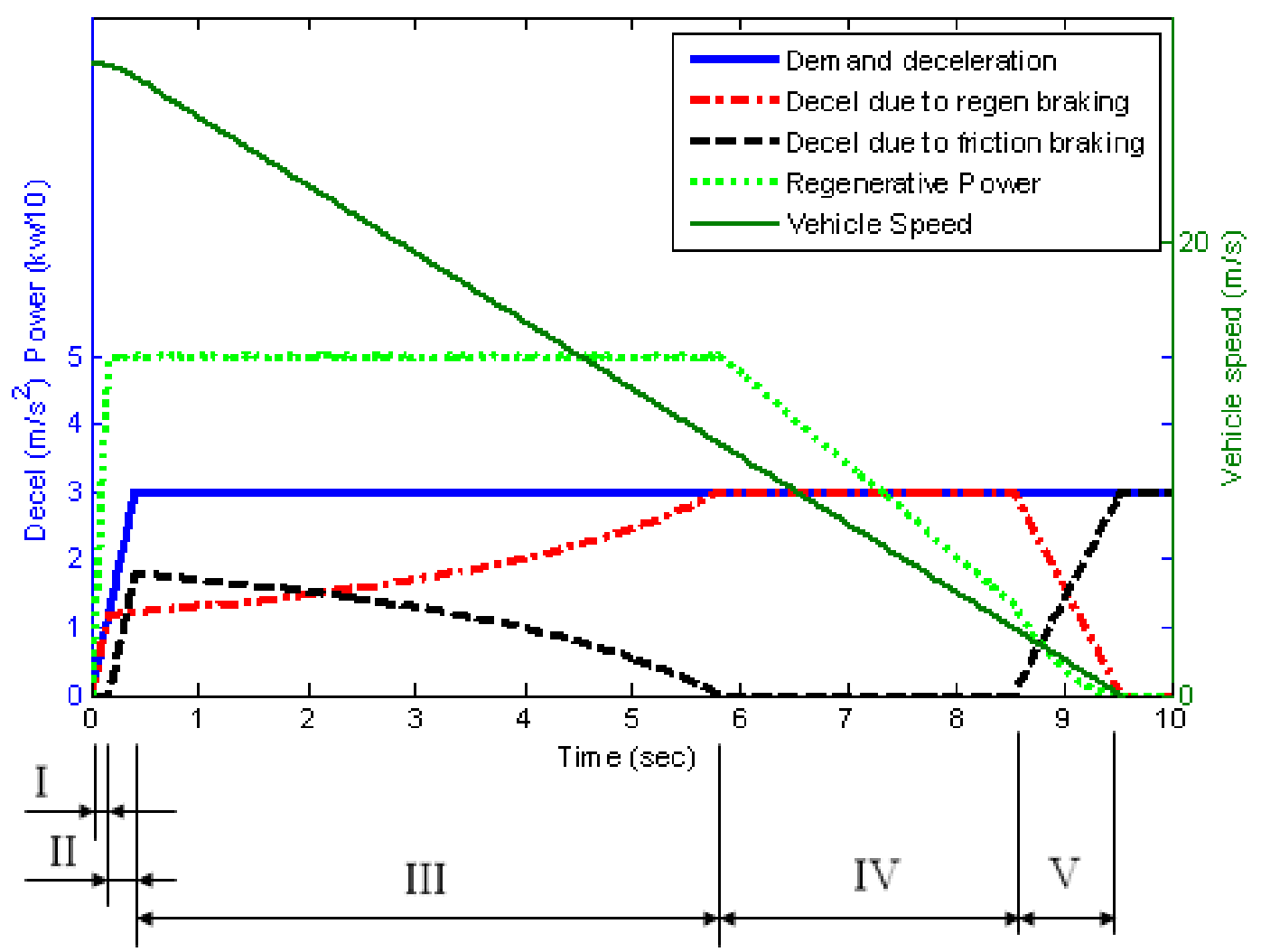

Fig. 2: Time histories of brake blending for a step deceleration input.

The situation is generally more complex in real-world driving, since the deceleration demand typically varies according to the driving conditions. For example, as the vehicle is approaching a complete stop, the driver normally releases and controls the brakes in order to stop gradually at a precise point. The control algorithm around this point is very sensitive to the estimates it has to make about the tyre/ground conditions and the anticipated stopping point - minor discrepancies can be sensed by the driver and it is probably around this region that Toyota had recent customer issues with the brake behaviour of the Prius and Lexus.

For vehicles with IWMs, it would generally be possible to control the MG unit to modulate the braking torque to achieve anti-lock braking [55]. However, since the hydraulic brakes will always have priority under emergency braking, the approach used is to simply disable the 
regeneration torque during anti-lock braking system (ABS) operation. The associated design challenge is that if the axle is using significant regenerative braking torque when wheel locking is sensed, it requires a rapid response to reduce the regenerative torque and replace it with a hydraulic braking torque.

The use of a conventional hydraulic braking system is generally able to provide a driver with a subjectively acceptable brake feel. If a portion of the braking force is generated by regeneration torque (with no automatic feedback to the driver), the brake pedal feel should be controlled independently by employing some type of haptic feedback. It has been assumed that the driver should be unaware of the ratio of how much braking is generated through regeneration and hydraulic braking, where the driver is only concerned with the overall braking performance and the confidence in being able to control it accurately [56].

Another issue has recently attracted concerns with fully electric vehicles. The level of regenerative braking applied, during overrun when the driver releases the accelerator pedal, is a design variable. Some vehicles (e.g. Prius) offer driver an option of moderate or more aggressive mode. The latter setting enhances the overall energy efficiency, while providing the driver with a different feel at the accelerator pedal, instead of the brakes. For example, the driver can control the early phase of braking at modest deceleration levels through the accelerator pedal release close to lift-off. Opinions still vary about the subjective feel of this arrangement, which is clearly different from conventional vehicles. Mercedes have taken this idea a stage further in the prototype SLS E-Cell and provided four levels of regenerative braking selected by a steering wheel-mounted paddle, to emulate changing down through the gears.

The integration of regenerative braking (generally inboard except IWMs) with hydraulic braking (outboard) may further necessitates a tuning refinement for suspension geometry and kinematics for achieving an acceptable level of vehicle anti-pitch properties without inducing much jerk motion. As mentioned in the last section, the IWM drive poses considerable challenges on the combined steering/suspension system and wheel vertical motion control, which could negatively affect both the vehicle braking performance and drivability. Planetary gear, popularly employed in power-split hybrid electric vehicles, suggests inherently low damping in driveline, which may induce torsional vibrations. Due to the closed-loop nature of power-split control, such torsional vibrations can lead to sustained oscillations of the driveline system, which would affect driver's comfort as well as vehicle drivability [57]. The study [57] explored active damping controls to effectively suppress the driveline oscillations.

A higher sprung mass combined with a higher vehicle c.g., due to the integration of electrified powertrains, tends to generate larger longitudinal load transfers during braking/traction manoeuvres, which thus deteriorates the vehicle braking/tractive performance, as well as vehicle handling balance and stability. Moreover, the difficulties associated with batteries layout and packaging yield a lower flexibility in tuning pitch moment of inertia of the sprung mass, and thus in the dynamics index, which has a strongly influence on vehicle pitch ride. The battery swapping concept indicates an extra compromise between the swapping operation flexibility and vehicle dynamics parameters tuning.

\section{IMPACT ON YAW-PLANE DYNAMICS AND CONTROLS}

Yaw-plane vehicle dynamics and controls are most critical in view of vehicle handling performance and directional stability, where the combined steady-state and transient steering/handling characteristics play the most important roles. A compromise between vehicle 
handling responsiveness and directional stability exists and should be balanced, where vehicle path, yaw rate and lateral acceleration are assumed to be closely related to responsiveness, while vehicle sideslip angle and roll angle are correlated to stability [58].

The steady-state vehicle steering/handling dynamic characteristics are dominated by a set of fundamental vehicle design and chassis tuning parameters, including geometrical parameters (e.g., wheelbase), front/rear load distribution ratio, tyre stiffness properties, front rear suspension roll stiffness distribution ratio, etc. Minimal variations on these design parameters, and thus on the steady-state vehicle steering/handling dynamics, could be achieved by an appropriate integration of electrified powertrains.

Unlike the steady-state characteristics, transient handling dynamics are also strongly affected by the mass and yaw moment of inertia properties of the vehicle and damping properties, apart from those fundamental vehicle design parameters. A vehicle with desirable transient handling dynamics should have the following expectations, as described in [59]:

"During transient events, drivers first expect the quickness in the lateral response of the front axle. The rear axle should be 'planted on ground' (i.e. the perceived vehicle yaw motion should pivot about the rear axle). Slow body roll motion should follow the front lateral motion, not precede it. Responses in all the channels should not have excessive overshoot (perceived as lack of precision and/or stability) and be smooth (without a two-stage feel). There should not be excessive roll, yaw, pitch or heave oscillation after the initial steer input."

The integration of electrified powertrains tends to alter the mass and yaw moment of inertia properties of the vehicles, which is thus expected to have an impact on the transient vehicle handling dynamics. Such impact would most likely be negative, due to the relatively less flexibility in the chassis layout and packaging by integrating electrified powertrains, as well as the heavy battery pack.

Control of the wheel/tyre longitudinal forces can influence the handling balance and thus directional stability of electric and hybrid vehicles, in three different ways: (a) If the front and rear axle torques can be controlled independently, the vehicle handling balance can then be tuned via the F:R torque balance that is currently popular in rallying using a controlled centre differential; (b) The amounts of regenerative braking at IWMs can be controlled to yield left/right asymmetric braking and thus an additional yaw moment; and (c) During normal driving, the driving torque at each wheel motor can be controlled. Again, this can be used in both two-wheel-drive (2WD) and four-wheel-drive (4WD) applications to achieve torque vectoring, i.e. the application of an additional yaw moment to influence the handling balance and directional stability. This approach can be used in two regimes: the low/mid lateral acceleration region to modify the vehicle steering feel, and the limit region to provide a yaw stability control.

\section{$\underline{F: R}$ Axle Balance}

Little effort has been attempted on this topic. The main application of tuning the F:R traction balance is in the rallying world. A number of hybrid electric vehicle designs add an additional electric drive to the axle not driven by the main IC engine, which tends to lead to potential problems by altering the $\mathrm{F}: \mathrm{R}$ traction balance suddenly as the electric motor torque is applied. 
However, in most applications, the electric motor torque is relatively smaller compared with that of the IC engine and the effect on the F:R balance is not normally problematic.

\section{Brake-Based Yaw Moment}

Brake-based yaw stability control (YSC) systems have been proposed as a requirement on future passenger cars, though these are historically known by a variety of alternative names (e.g. ESC, VSC, DYC, etc.) from different vehicle manufacturers. To ensure stability under emergency conditions, these safety systems will continue to be fitted to vehicles, irrespective of powertrain architecture. Therefore, while the topic of yaw stability and control has been discussed in relation to controlling regenerative braking at individual wheels, it seems unlikely that asymmetric braking using regenerative torques will offer any additional benefits to the conventional YSC systems [60, 61].

\section{Torque-Based Yaw Moment}

Electric motors offer a considerably potential advantage in providing torque vectoring control. Although the subject of Variable Torque Distribution (VTD) has received a substantial amount of attention mainly through analytical studies, its commercial applications has been hindered due to the difficulties associated with the hardware. A very recent study [62] reviewed different active driveline torque management systems, including centre couplings, electronic limited-slip differentials (ELSDs), and torque vectoring systems. Electronically controlled differentials have been available for several years, but their uptake has been limited by high costs and the inevitable energy losses involved in their design.

Both these drawbacks are overcome by the use of IWMs. The potential for using electric motors for controlling vehicle handling has been dealt with in a number of studies, often as an extension of investigating traction control at an individual wheel [63]. Moreover, practical implementations have been carried out on both small scale electric vehicles [64, 65] and prototype passenger electric vehicles [66]. IWM drive clearly offers significant advantages in VTD schemes [67], which also overcomes the practical drawbacks of mechanical-based systems.

However, despite the significant volume of theoretical studies of torque vectoring on vehicle handling control, there is not a widely accepted design methodology of how to exploit it to improve vehicle handling and stability significantly $[68,69]$. IWMs have really opened up the practical opportunity for individual force control at the four wheels of a vehicle [70,71] - but it is a dynamics challenge to understand the driver-vehicle interaction issues to exploit it as a measurable handling benefit $[20,21,72,73]$.

Abe et al. [20] proposed a method to evaluate vehicle handling qualities based on a closed-loop driver-vehicle system using a simplified driver model (with three parameters). These three parameters are related to human driver's steering gain, time preview and time lag, respectively. The steering gain of human drivers could vary significantly with little workload. However, the time preview and time lag characteristic of human drivers during driving could be associated to the workload, e.g., a larger time preview or a smaller time lag could indicate a higher workload or a more stressful driving. The study [20] showed that drivers could adapt themselves (reflected on the variations of the three parameters of the driver model) to the vehicle with/without chassis controls. The chassis control systems considered in the study [20] could help reduce drivers' workload and thus improve the vehicle handling quality. 
The very high responsiveness of electric motor drive may allow human drivers to have a relatively larger time lag (especially beneficial for aged drivers) and thus reduced driving workload. Instead of driver's adaptation to a vehicle with conventional chassis controls, chassis controllers design based on a closed-loop driver-vehicle system would be expected to considerably improve the total vehicle dynamics performance and stability. An enhanced understanding of human drivers' physiological limits and driving behaviours is thus becoming important [74].

\section{DISCUSSIONS ON REGENERATIVE SUSPENSION}

Vehicle electrification offers an excellent opportunity to integrate suspension energy regeneration function, apart from the regenerative braking. However, compared to braking, power dissipation due to a vehicle suspension damper could be much smaller. A brief review on the energy consumption in vehicle suspensions and regenerative suspension systems was conducted in [3]. For a particular passenger car, the power dissipation due to the suspension system is about $80 \mathrm{~W}$ and $100 \mathrm{~W}$ at $50 \mathrm{~km} / \mathrm{h}$ and $100 \mathrm{~km} / \mathrm{h}$, respectively [75], which is at the similar level to that stated in [4].

In order to quantify the level of power dissipation due to vehicle suspension, a dimensionless measure, coefficient of suspension motion resistance (SMR), is defined in this study, which is the drive force that is used to compensate the energy dissipated in the suspension damper normalized by the vehicle weight. It is quite similar to the definition of coefficient of tyre rolling resistance. A classic four degree-of-freedom (DOF) pitch-plane vehicle ride model (e.g. in [37]) is used to investigate the SMR properties under random road inputs. The measured roughness data of three different urban roads [34] are considered for the simulation analyses. Figure 3 illustrates the spatial displacement power spectral density (PSD) characteristics of the three road profiles. Based on their relative spatial displacement PSD properties, these three selected roads are named as "smooth", "medium-rough" and "rough", respectively, as shown in Fig. 3.

Figure 4 presents the SMR properties of a road vehicle, under the three different road inputs and five different vehicle speeds $(30,50,70,90$, and $110 \mathrm{~km} / \mathrm{h})$. The results show that an increase in vehicle speed or road roughness tends to increase the SMR. However, the SMR is generally less than $10 \%$ of the typical rolling resistance of a passenger tyre (about 0.01 ), for the measured urban road data considered. To give a general sense of roughness levels of the three roads, the vertical accelerations of the sprung mass at the speed of $90 \mathrm{~km} / \mathrm{h}$, are at the levels of $0.28,0.6$ and $1.15 \mathrm{~m} / \mathrm{s}^{\wedge} 2$, respectively, for the three roads considered here. It should be noted that both the suspension tuning and wheelbase filtering have relatively small effects on the overall SMR characteristics of the vehicle, which are not presented here.

Based on the above discussions, the potential of integrating a regenerative suspension within a vehicle should be justified, in terms of the added weight and cost, the efficiency and reliability of the whole regeneration system, as well as the vehicle operating conditions. Regenerative suspension might hold the most potential for high-speed off-road vehicle applications, such as military vehicles and SUVs. 


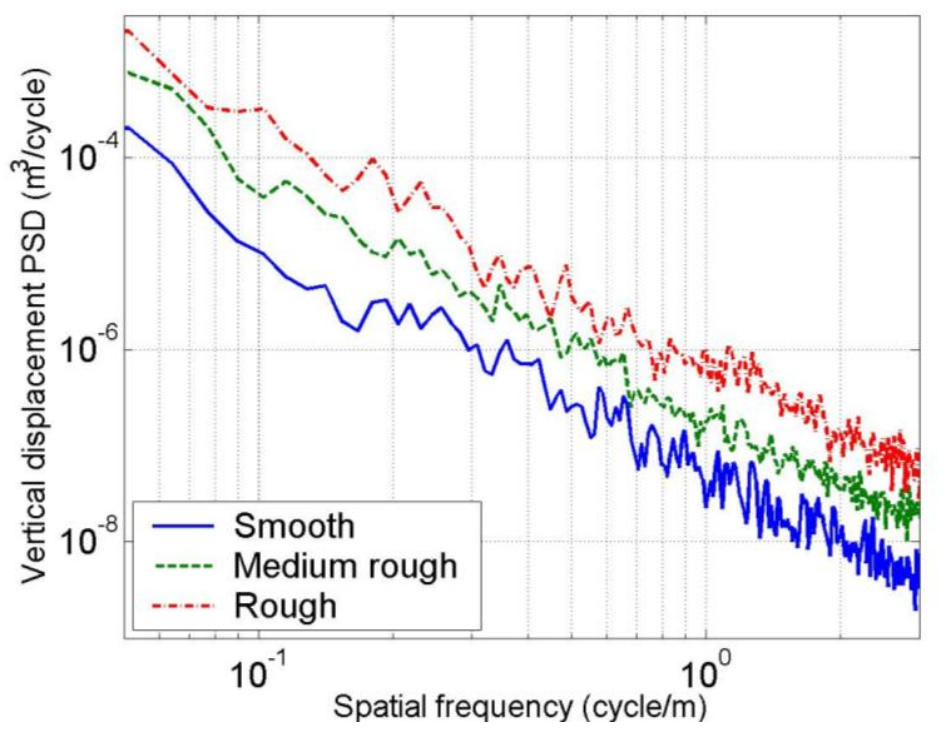

Fig. 3: Spatial roughness PSD of three measured urban road profiles.

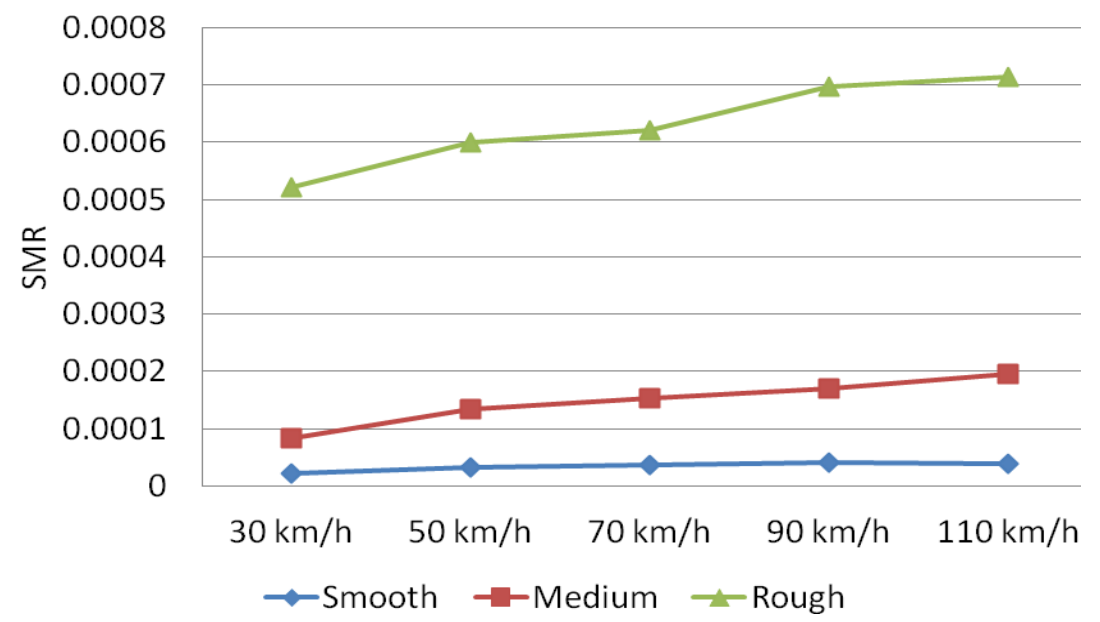

Fig. 4: SMR characteristics of a road vehicle under different road inputs and different speeds.

\section{CONCLUSIONS}

This paper reviewed the impact of the electrified powertrains on the vehicle dynamics and controls, and particularly examined the influence on vehicle ride, handling and stability performance, and energy regeneration. In a summary:

- In the longitudinal direction, electric motors provide improved torque control which benefits TCS and provides regenerative braking, but to date has not been used to improve ABS;

- In view of ride vibration and comfort, the two main issues are increased body and unsprung masses. Further research is required to quantify these effects, but the increase in unsprung mass is almost certain to result in a deterioration in the ride/handling compromise;

- In view of handling and stability, individual wheel motor drive provides significant benefits in providing torque vectoring to enhance vehicle handling and stability. The 
challenge is to identify how to exploit torque vectoring to offer handling/stability benefits which are noticeable to customers;

- Regenerative suspension might hold the most potential for high-speed off-road vehicle applications;

- Chassis and powertrain control systems should be coordinated so as to enhance both the vehicle dynamics/stability and energy efficiency.

- An enhanced understanding of driver-vehicle interactions is one of the most emerging topics in modern vehicle dynamics and controls.

\section{Acknowledgement}

This manuscript was initiated by Prof. Crolla, who very sadly passed away on September 4, 2011, due to a heart attack when cycling. The co-author, Dongpu Cao, sincerely appreciates the very kind guidance from Prof. Crolla, in vehicle dynamics and controls.

\section{References}

1. C.C. Chan, Y.S. Wong, A. Bouscayrol and K. Chen: Powering sustainable mobility: roadmaps of electric, hybrid, and fuel cell vehicles, Proceedings of the IEEE, 97, 2009, p. 603-607.

2. A. Subic and L. Koopmans: Global green car learning clusters, International Journal of Vehicle Design, 53, 2010, p. 36-53.

3. D. Cao, X. Song and M. Ahmadian: Editors' perspectives: road vehicle suspension design, dynamics, and control, Vehicle System Dynamics, 49, 2011, p. 3-28.

4. J. Rauh and D. Ammon: System dynamics of electrified vehicles: some facts, thoughts, and challenges, Vehicle System Dynamics, 49, 2011, p. 1005-1020.

5. D.A. Crolla, Q. Ren, S. El Demerdash and F. Yu: Controller design for hybrid vehicles State of the art review, Proceedings of IEEE Vehicle Power and Propulsion Conference (VPPC), Sep 3-5, 2008, Harbin, China.

6. K.T. Chau and W. Li: Overview of electric machines for electric and hybrid vehicles, International Journal of Vehicle Design. (in press)

7. A.F. Burke: Batteries and ultracapacitors for electric, hybrid, and fuel cell vehicles, Proceedings of the IEEE, 95, 2007, p. 806-820.

8. S.A. Beiker and R.C. Vachenauer: The impact of hybrid-electric powertrains on chassis systems and vehicle dynamics, SAE Paper 2009-01-0442, 2009.

9. D.A. Crolla: Vehicle dynamics - theory into practice, IMechE Part D Journal of Automobile Engineering, 210, 1996, p. 83-94.

10. J. Rauh: Virtual development of ride and handling characteristics for advanced passenger cars, Vehicle System Dynamics, 40, 2003, p. 135-155.

11. T.J. Gordon and M.C. Best: On the synthesis of driver inputs for the simulation of closedloop handling maneuvers, International Journal of Vehicle Design, 40, 2006, p. 52-76.

12. O. Mokhiamar and M. Abe: How the four wheels should share forces in an optimum cooperative chassis control, Control Engineering Practice, 14, 2006, p. 295-304.

13. M. Jonasson, J. Andreasson, B. Jacobson and A. Stesson Trigell: Global force potential of over-actuated vehicles, Vehicle System Dynamics, 48, 2010, p. 983-998.

14. R.S. Sharp and H. Peng: Vehicle dynamics applications of optimal control theory, Vehicle System Dynamics, 49, 2011, p. 1073-1111. 
15. M. Klomp and R. Thomson: Influence of front/rear drive force distribution on the lateral grip and understeer of all-wheel drive vehicles, International Journal of Vehicle Design, 56, 2011, p. 34-48.

16. Y.A. Ghoneim, W.C. Lin, D.M. Sidlosky, H.H. Chen, Y.-K. Chin and M.J. Tedrake: Integrated chassis control system to enhance vehicle stability, International Journal of Vehicle Design, 23, 2000, p. 124-144.

17. A. Hac and M.O. Bodie: Improvements in vehicle handling through integrated control of chassis systems, International Journal of Vehicle Design, 29, 2002, p. 23-50.

18. A. Trachtler: Integrated vehicle dynamics control using active brake, steering and suspension systems, International Journal of Vehicle Design, 36, 2004, p. 1-12.

19. J.H. Plumlee, D.M. Bevly and A.S. Hodel: Control allocation in ground vehicles, International Journal of Vehicle Design, 43, 2006, p. 215-243.

20. J. Ishio, H. Ichikawa, Y. Kano and M. Abe: Vehicle-handling quality evaluation through model-based driver steering behaviour, Vehicle System Dynamics, 46 (Supplement), 2008, p. 549-560.

21. Y. Aoki, Y. Kano and M. Abe: Variable stability vehicle with response parameters controlled by active chassis control devices, IAVSD 2011, Paper No. IAVSD2011-0108, August, 2011, Manchester, UK.

22. M. Nagai: The perspectives of research for enhancing active safety based on advanced control technology, Vehicle System Dynamics, 45, 2007, p. 413-431.

23. S. Sakai and Y. Hori: Advanced motion control of electric vehicle with fast minor feedback loops: basic experiments using the 4 wheel motored EV 'UOT Electric March II', Japan Soc Auto Engnrs Review, 22, 2001, p. 527-536.

24. S. Murata: Electric drive - innovation by in-wheel motor drive unit, Keynote Presentation, Proceedings of AVEC 2010, Loughborough, England, 2010.

25. R. Saeks and C.J. Cox: Design of an adaptive control system for a hybrid electric vehicle, Proceedings of IEEE Conf Systems, Man and Cybernetics, 1999.

26. R. Saeks, C.J. Cox, J. Neidhoefer, P.R. Mays and J.J. Murray: Adaptive control of a hybrid vehicle, IEEE Trans Intelligent Transportation Systems, 3, 2002, p. 213-234.

27. J. Fredriksson, J. Andreasson and L. Laine: Wheel force distribution for improved handling in a Hybrid Electric Vehicle using nonlinear control, The $43^{\text {rd }}$ IEEE Conf on Decision and Control, p. 4081-4086, Dec 2004.

28. K. Nam, S. Oh and Y. Hori: Robust yaw stability control for electric vehicles based on active steering control, Proceedings of IEEE Vehicle Power and Propulsion Conference (VPPC), Sep 1-3, 2010, p. 1-5, Lille, France.

29. M. Jonasson and O. Wallmark: Control of electric vehicles with autonomous corner modules; implementation aspects and fault handling, International Journal of Vehicle Systems Modelling and Testing. 3, 2008, p. 213-228.

30. N. Mutoh, Y. Takahashi and Y. Tomita: Failsafe drive performance of FRID electric vehicles with the structure driven by the front and rear wheels independently, IEEE Transactions on Industrial Electronics, 55, 2008, p. 2306-2315.

31. T. Armstrong, W. Manning, I. Hogan and A. Shenfield: Vehicle dynamics control in hybrid electric vehicles, Proceedings of AVEC 2010, p. 514-519, Loughborough, England, 2010.

32. M. Ringdorfer and M. Hom: Vehicle dynamics controller concept for electric vehicles, Proceedings of AVEC 2010, p. 675-680, Loughborough, England, 2010.

33. H. Niederkopfler, R. Rojas and E. Andres: Towards ecorner: energy efficient design of mechatronic suspension systems, FISITA Congress 2010, Paper No. F2010-C-195, Budapest, Hungary, 2010. 
34. D. Cao, S. Rakheja and C.-Y. Su: Roll plane analysis of a hydro-pneumatic suspension with twin-gas-chamber struts, International Journal of Heavy Vehicle Systems, 14, 2007, p. 355375.

35. R. Vos, I. Besselink and H. Nijmeijer: Influence of in-wheel motors on the ride comfort of electric vehicles, AVEC 2010, Loughborough, UK, 2010, p. 835-840.

36. D. Harty and M. Anderson: Unsprung mass with wheel motors - myths and realities, Proceedings of AVEC 2010, Loughborough, UK, 2010, p. 261-266.

37. D.A. Crolla and R.P. King: Olley's 'flat ride' revisited, Vehicle System Dynamics, 33 (Supplement), 1999, p. 762-774.

38. Y. Hori, Y. Toyoda and Y. Tsuruoka: Traction control of electric vehicle based on the estimation of road surface condition, Proceedings of IEEJ-IEEE Power Conversion Conf, 1997, p. 1-8.

39. Y. Hori, Y. Toyoda and Y. Tsuruoka: Traction control of electric vehicle: Basic experimental results using the EV 'UOT Electric March', IEEE Transactions on Industry Applications, 34, 1998, p. 1131-1138.

40. S. Sakai and Y. Hori: Advantage of electric motor for antiskid control of electric vehicle, European Electronics Power Journal, 11, 2001, p. 26-32.

41. T. Saito, H. Fujimoto and T. Noguchi: Yaw moment stabilisation control of small electric vehicle, Proceedings of IEE Industrial Instrumentation and Control, Japan, 2002, p. 83-88.

42. T. Akiba, R. Shirato, T. Fujita and J. Tamura: A study of novel traction control model for electric motor driven vehicle, Proceedings of the 4th Power Conversion Conference, Nagoya, Japan, 2007, p. 699-704.

43. L. Li, S. Kodama and Y. Hori: Design of antislip controller for an electric vehicle with an adhesion status analyzer based on the EV simulator, Asian Journal of Control, 8, 2006, p. 261-267.

44. K. Hartani, M. Bourahla and Y. Miloud: New antiskid control for electric vehicle using behaviour model control based on energetic macroscopic representation, Journal of Electrical Engineering, 59, 2008, p. 225-233.

45. D. Yin and Y. Hori: A novel traction control of EV based on maximum effective torque estimation, IEEE VPPC, Harbin, China, Sep 2008.

46. D. Yin and Y. Hori: A novel traction control without chassis velocity for electric vehicles, Proceedings of EVS24, Stavanger, Norway, May 2009.

47. D. Yin and Y. Hori: A novel traction control for electric vehicle without chassis velocity, Chapter 6, Motion Control, ed Fredirico Casolo, INTECH, Croatia, 2010.

48. F. Wang and B. Zhuo: Regenerative braking strategy for hybrid electric vehicles based on regenerative torque optimisation control, IMechE Part D Journal of Automobile Engineering, 222, 2008, p. 499-513.

49. J. Hellgren and E. Jonasson: Maximisation of brake energy regeneration in a hybrid electric parallel car, International Journal of Electric and Hybrid Vehicles, 1, 2007, p. 95-121.

50. H. Yeo, S. Hwang and H. Kim: Regenerative braking algorithm for a hybrid electric vehicle with CVT ratio control, IMechE Part D Journal of Automobile Engineering, 220, 2006, p. 1589-1600.

51. E. Cacciatori, B. Bonnet, N.D. Vaughan, M. Burke, D. Price and K. Wejrzanowski: Regenerative braking strategies for a parallel hybrid powertrain with torque controlled IVT, SAE Paper 2005-01-3826, 2005.

52. Y. Gao and M. Ehsani: Electronic braking system of EV and HEV - integration of regenerative braking, automatic braking force control and ABS, SAE Paper 2001-01-2478, 2001.

53. E. Nakamura, M. Soga, A. Sakaki, A. Otomo and T. Kobayashi: Development of electronically controlled brake system for hybrid vehicle, SAE Paper 2002-01-0900, 2002. 
54. J.K. Ahn, K.H. Jung, D.H. Kim, H.B. Jin, H.S. Kim and S.H. Hwang: Analysis of a regenerative braking system for hybrid electric vehicles using an electromechanical brake, International Journal of Automotive Technology, 10, 2009, p. 229-234.

55. S. Sakai, H. Sado and Y. Hori: Novel skid avoidance method for electric vehicle with independently controlled 4 in wheel motors, Proceedings of IEEE Industrial Electronics, Bled, Slovenia, 1999, p. 934-939.

56. A. Newberry: Characterisation of brake feel for hybrid vehicles, Proceedings of AVEC 2010, Loughborough, UK, 2010, p. 592-597.

57. F.U. Syed, M.L. Kuang and H. Yang: Active damping wheel-torque control system to reduce driveline oscillations in a plower-split hybrid electric vehicle, IEEE Transactions on Vehicular Technology, 58, 2009, p. 4769-4785.

58. E. Bedner, D. Fulk and A. Hac: Exploring the trade-off of handling stability and responsiveness with advanced control systems, SAE Paper 2007-01-0812, 2007.

59. X. Wu, M. Farhad and J.M. Wong: Investigating and improving vehicle transient handling performance, SAE Paper 2011-01-0987, 2011.

60. D. Kim and H. Kim: Vehicle stability control with regenerative braking and electronic brake force distribution for a four wheel drive electric vehicle, IMechE Part D Journal of Automobile Engineering, 220, 2006, p. 683-693.

61. D.-H. Kim, J.-M. Kim, S.-H. Hwang and H.-S. Kim: Optimal brake torque distribution for a four wheel drive hybrid electric vehicle stability enhancement, IMechE Part D Journal of Automobile Engineering, 221, 2007, p. 1357-1366.

62. D. Piyabongkarn, J.Y. Lew, R. Rajamani and J.A. Grogg: Active driveline torquemanagement systems, IEEE Control Systems Magazine, 30, 2010, p. 86-102.

63. S. Sakai, H. Sado and Y. Hori: Motion control in an electric vehicle with four independently driven in-wheel motors, IEEE/ASME Transactions on Mechatronics, 4, 1999, p. 9-16.

64. M. Shino and M. Nagai: Independent wheel torque control of small scale electric vehicle for handling and stability management, JSAE Review, 24, 2003, p. 449-456.

65. H. Fujimoto, T. Saito and T. Noguchi: Motion stabilization control of electric vehicle under snowy conditions based on yaw moment observer, IEE Int. Workshop on Advanced Motion Control, 2004, p.35-40.

66. P. He and Y. Hori: Optimum traction force distribution for stability improvement of 4WD EV in critical driving condition, Proceedings of AMC 06, Turkey, 2006, p. 598-601.

67. R. Rieveley and B.P. Minaker: Variable torque distribution yaw moment control for hybrid powertrains, SAE Paper 2007-01-0278, 2007.

68. M. Milehins, C. Cheng, T.-W. Chu and R.P. Jones: Handling behaviour of a TTR hybrid electric vehicle with independent rear wheel torque control, Proceedings of AVEC 2010, Loughborough, UK, 2010, p. 556-561.

69. L. Pinto, S. Aldworth, M. Watkinson, P. Jeary and M. Franco-Jorge: Advanced yaw motion control of a hybrid vehicle using twin rear electric motors, Proceedings of AVEC 2010, Loughborough, UK, 2010, p. 640-645.

70. L. Xiong, Z. Yu and Y. Meng: Vehicle dynamic control for a 4 in-wheel-motored EV based on identification of tyre cornering stiffness, Proceedings of AVEC 2010, Loughborough, UK, 2010, p. 861-866.

71. F. Braghin and F. Sabbioni: Development of a control strategy for improving vehicle safety in a hybrid vehicle with four independently driven in-wheel motors, Proceedings of AVEC 2010, Loughborough, UK, 2010, p. 91-96.

72. K.H. Guo, C.F. Zong, F.S. Kong and M.L. Chen: Objective evaluation correlated with human judgment - an approach to the optimisation of vehicle handling control system, International Journal of Vehicle Design, 29, 2002, p. 96-111. 
73. R. Powell, B. Ayalew and E.H. Law: Relationships between lane change performance and open-loop vehicle handling metrics, International Journal of Vehicle Design, 56, 2011, p. 1933.

74. D.J. Cole: A path-following driver-vehicle model with neuromuscular dynamics, including measured and simulated responses to a step in steering angle overlay, Vehicle System Dynamics. (in press)

75. I.D.B. Carruthers: Simulation and testing of energy dissipation in passenger vehicle dampers, Master thesis, Queen's University, Canada, 2005.

\section{Definitions, Acronyms and Abbreviations}

$\begin{array}{ll}\text { ABS: } & \text { Anti-lock braking system } \\ \text { AFS: } & \text { Active front steering } \\ \text { ARC: } & \text { Active roll control } \\ \text { CVT: } & \text { Continuously variable transmissions } \\ \text { DYC: } & \text { Direct yaw control } \\ \text { ELSD: } & \text { Electronic limited-slip differential } \\ \text { ESC: } & \text { Electronic stability control } \\ \text { ESP: } & \text { Electronic stability program } \\ \text { FWD: } & \text { Front-wheel-drive } \\ \text { ICEV: } & \text { Internal combustion engine vehicle } \\ \text { ISA: } & \text { Integrated starter alternator } \\ \text { IVT: } & \text { Infinitely variable transmissions } \\ \text { IWM: } & \text { Individual wheel motor } \\ \text { MFC: } & \text { Model following control } \\ \text { MG: } & \text { Motor/generator } \\ \text { MTTE: } & \text { Maximum transmittable torque estimation } \\ \text { RWD: } & \text { Rear-wheel-drive } \\ \text { SMR: } & \text { Suspension motion resistance } \\ \text { SOC: } & \text { Battery state of charge } \\ \text { TCS: } & \text { Traction control system } \\ \text { VSC: } & \text { Vehicle stability control } \\ \text { VTD: } & \text { Variable torque distribution } \\ \text { YSC: } & \text { Yaw stability control } \\ \text { 2WD: } & \text { Two-wheel-drive } \\ \text { 4WD: } & \text { Four-wheel-drive }\end{array}$

